Website: ijetms.in Issue:5, Volume No.4, September-2020 DOI: 10.46647/ijetms.2020.v04i05.005

\title{
A NOVEL ENHANCED MPPT METHOD COMBINING FRACTIONAL-ORDER AND FUZZY LOGIC CONTROL
}

\author{
Dr. S. VIJAYA KUMAR \\ ASSISTANT PROFESSOR \\ Dr. KV S R INSTITUTE OF TECHNOLOGY, \\ KURNOOL, AP, INDIA
}

\author{
M. MADHU SUDHAN REDDY \\ ASSISTANT PROFESSOR \\ Dr. KV S R INSTITUTE OF TECHNOLOGY, \\ KURNOOL, AP, INDIA
}

Abstract

A fractional-order fuzzy logic control (FOFLC) method for maximum power point tracking (MPPT) in a photovoltaic (PV) system is presented. By combining the robustness of fuzzy logic with the accuracy of fractional order, the proposed method can improve the tracking accuracy in weather variations compared with the conventional fuzzy MPPT. First, the fractionalorder factor is carefully selected according to the dynamic range of the fuzzy controller. It takes a bigger alpha factor in the first place to expand the fuzzy domain and shortens the time of searching for the MPP. When the maximum power point is approached, it uses a smaller the alpha factor to contract the fuzzy domain and eliminates the oscillations at the MPP. Therefore, the FOFLC in a PV system has rapid dynamic responses under environment variations and high tracking accuracy of the maximum power point. Second, MATLAB/Simulink software is employed to simulate a PV power system and verify the proposed algorithm by various simulations. The enhanced MPPT algorithm has been implemented on a field programmable gate array (FPGA) board. Finally, a boost dc-dc converter experiment has been carried out to evaluate the system performance. The simulation and experiment results show that this method can improve the transient and steady-state performance simultaneously.

INTRODUCTION
AN actual physical system, many environmental factors impact fractional-order (FO) behavior, such as heat transfer and electromagnetic wave in solids [1]. A photovoltaic (PV) cell is a kind of semiconductor material (monocrystalline or polycrystalline silicon) in which photocurrent can cross the p-n junction of the energy gap. Hence, the characteristic between PV diffusion current and ambient conditions (solar radiation, temperature) can be described by dynamic behaviors as FO diffusion [2], [3]. The mathematical model of an FO form approximately describes the diffusion phenomenon of a solar cell [4]. It is required to keep a PV system operation near the maximum power point (MPP) to maximize its power efficiency. Many MPP tracking (MPPT) algorithms have been implemented in PV systems such as perturbation and observation /hill climbing [5], incremental conductance (IncCond) [6], constant or fractional voltage/current [7], [8], and particle swarm optimization (PSO) [9]. The suitable FO factor can enhance the accuracy of MPPT by the reasonable approximations of FO calculus [2][4]. The FOICM (FO IncCond method) is based on the FO incremental changes of the PV array current and voltage at the MPP [2]. Yu et al. have improved the FO incremental changes by variable fractional order [3] and chaos synchronization dynamic error [4]. Different from the fractional current/voltage [7], [8], the FO method avoids measuring the short-circuit 
Website: ijetms.in Issue:5, Volume No.4, September-2020 DOI: 10.46647/ijetms.2020.v04i05.005

current and open-circuit voltage [2]-[4]. The FO IncCond algorithm is theoretically concise and effective, but the performance lacks robustness. Compared with these controllers, robust fuzzy logic controllers (FLCs) have been more suitable for MPPT [10]-[13]. An FLC requires less knowledge of the PV system mathematical model and provides better performances under changing atmospheric conditions [10]-[13]. However, the main drawback of conventional FLCs is fixed on fuzzy field [10]-[13]. To overcome this problem, some variable universal scaling factors are tuned online and the scaling input domain and output domain are calculated [12], [13]. Undoubtedly, how to choose a scalable factor is a challenged issue practically according to the nonlinear characteristic of PV system

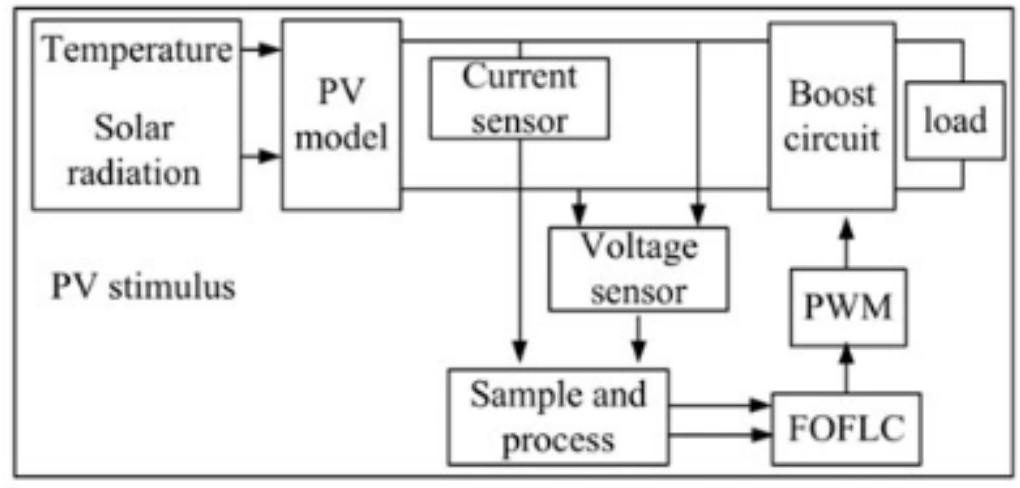

Fig 1 proposed system configuration

Photovoltaic cell and array modeling A $\mathrm{PV}$ cell is a simple $\mathrm{p}$ - $\mathrm{n}$ junction diode that converts the irradiation into electricity. Fig. 3.2 illustrates a simple equivalent circuit diagram of a PV cell. This model consists of a current source which represents the generated current from PV cell, a diode in parallel with the current source, a shunt resistance, and a series resistance

The continuous increase in the electrical energy with the clean environment needs the decentralized renewable energy production. The increasing energy consumption may overload the distribution grid as well as power station and may cause the negative impact on power availability, security and quality. The only solution to overcome this problem is integrating the utility grid with the renewable energy systems like solar, wind or hydro. The grid 1 can be connected to the renewable energy system as per the availability of renewable energy sources. Recently the solar power generation systems are getting more attention because solar energy is abundantly available, more efficient and more environment friendly as compared to the conventional power generation systems such as fossil fuel, coal or nuclear. The PV systems are still very expensive because of higher manufacturing cost of the PV panels, but the energy that drives them -the light from the sun- is free, available almost everywhere and will still be present for millions of years, even all non-renewable energy sources might be depleted. One of the major advantages of PV technology is that it has no moving parts. Therefore, the PV system is very robust, it has a long lifetime and low maintenance requirements. And, most importantly, it is one solution that offers environmentally friendly power generation. 
Website: ijetms.in Issue:5, Volume No.4, September-2020 DOI: 10.46647/ijetms.2020.v04i05.005

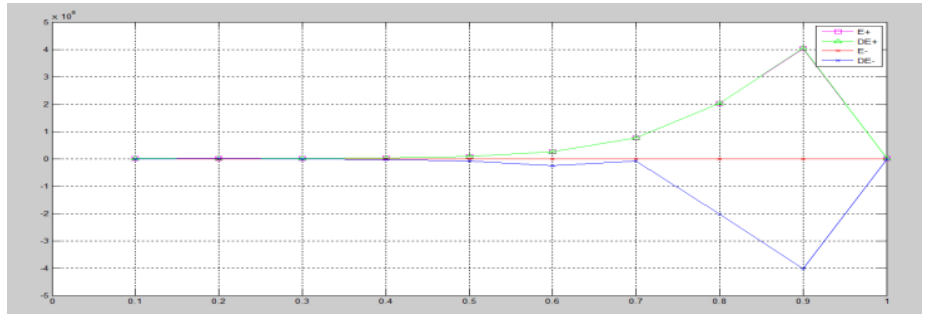

Fig 2 error change in error vs time

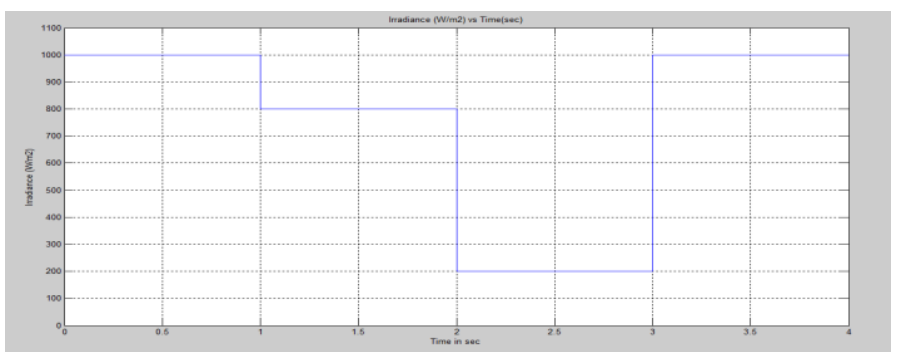

Fig 3 irradiance vs time

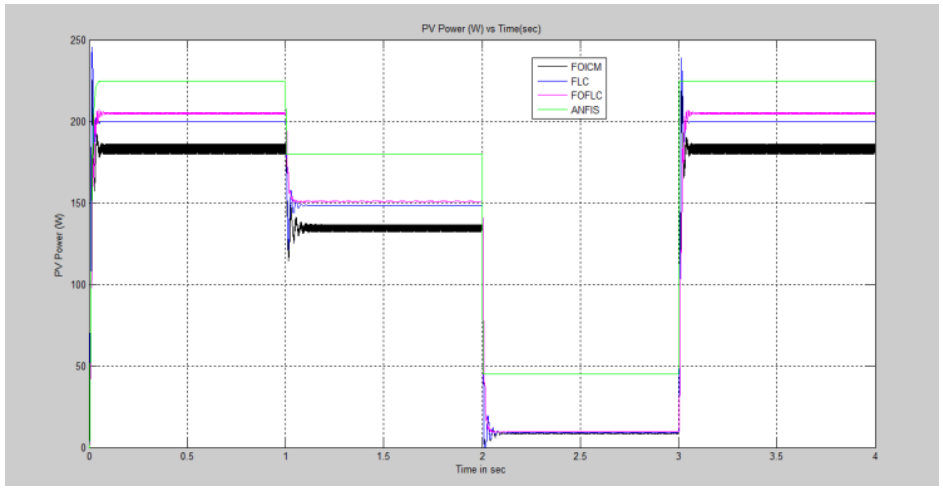

Fig 4 pv power vs time dynamic state

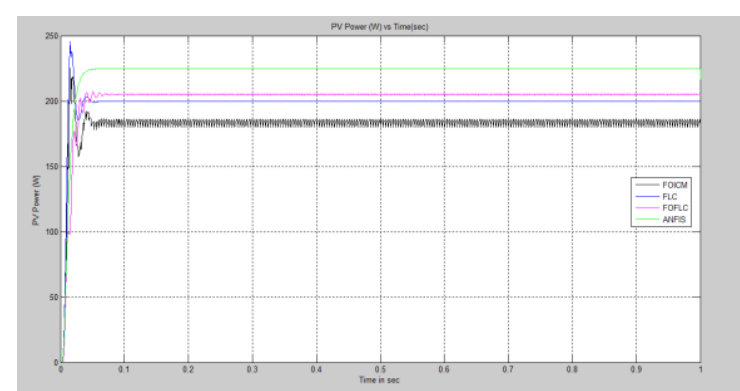

Fig 5 pv power vs time steady state 


\section{International Journal of Engineering Technology and Management Sciences[IJETVIS]}

Website: ijetms.in Issue:5, Volume No.4, September-2020 DOI: 10.46647/ijetms.2020.v04i05.005

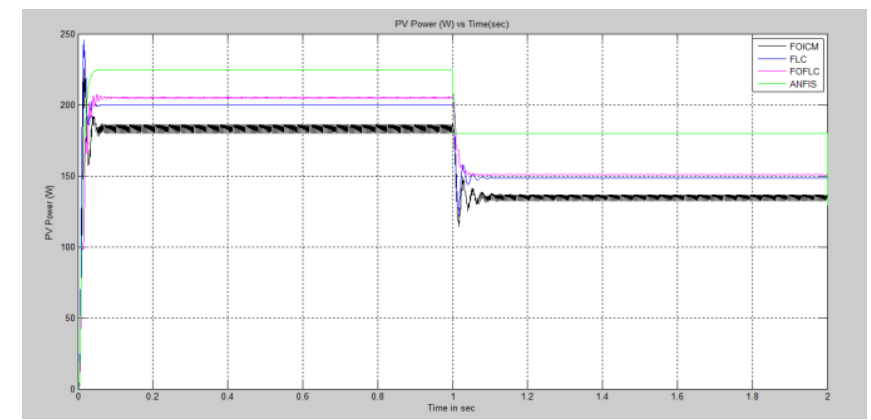

Fig 6 pv power vs time dynamic state

\section{FUZZY LOGIC}

As of late, the number and assortment of uses of Fuzzy logichave expanded fundamentally. The applications range from buyer items, for example, cameras, camcorders, clothes washers, and microwave stoves to mechanical procedure control, therapeutic instrumentation, choice emotionally supportive networks, and portfolio choice. To comprehend why utilization of Fuzzy logichas developed, you should first comprehend what is implied by fluffy rationale. Fuzzy logichas two unique implications. In a tight sense, Fuzzy logicis a coherent framework, which is an augmentation of multivalve rationale. In any case, in a more extensive sense Fuzzy logic(FL) is verging on synonymous with the hypothesis of fluffy sets, a hypothesis which identifies with classes of items with un sharp limits in which enrollment involves degree. In this viewpoint, Fuzzy logicin its slender sense is a branch of $\mathrm{fl}$. Indeed, even in its more limited definition, Fuzzy logicvaries both in idea and substance from conventional multivalve consistent frameworks. In fluffy Logic Toolbox programming, Fuzzy logicought to be translated as FL, that is, Fuzzy logic in its wide sense. The essential thoughts fundamental FL are clarified plainly and sagaciously in Foundations of Fuzzy Logic. What may be included is that the essential idea hidden FL is that of a phonetic variable, that is, a variable whose qualities are words as opposed to numbers. As a result, quite a bit of FL might be seen as a technique for processing with words instead of numbers. In spite of the fact that words are intrinsically less exact than numbers, their utilization is nearer to human instinct. Besides, registering with words misuses the resistance for imprecision and along these lines brings down the expense of arrangement. Another fundamental idea in FL, which assumes a focal part in a large portion of its applications, is that of a fluffy if-then administer or, just, fluffy tenet. Despite the fact that principle based frameworks have a long history of utilization in Artificial Intelligence (AI), what is lost in such frameworks is an instrument for managing fluffy consequents and fluffy forerunners. In fluffy rationale, this system is given by the math of fluffy standards. The math of fluffy guidelines serves as a premise for what may be known as the Fuzzy Dependency and Command Language (FDCL). Despite the fact that FDCL is not utilized expressly as a part of the tool kit, it is viably one of its chief constituents. In the vast majority of the uses of fluffy rationale, a Fuzzy logic arrangement is, actually, an interpretation of a human arrangement into FDCL. 
Website: ijetms.in Issue:5, Volume No.4, September-2020 DOI: 10.46647/ijetms.2020.v04i05.005

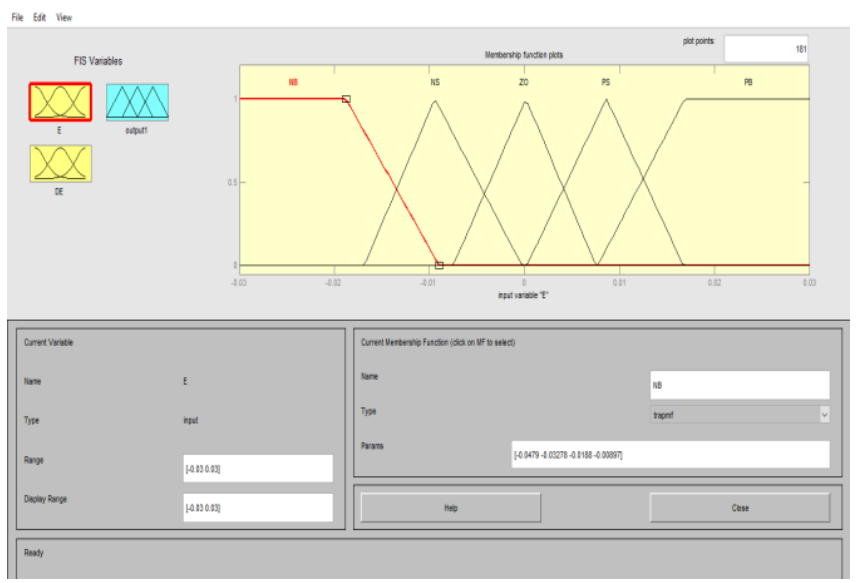

Fig 7 error rules

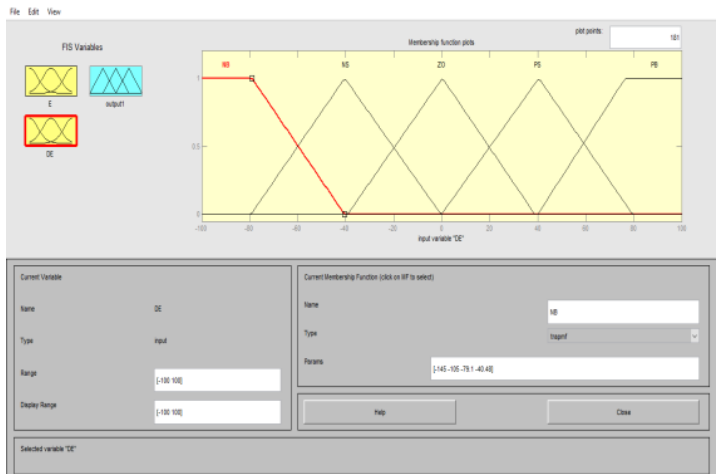

Fig 8 change in input rules

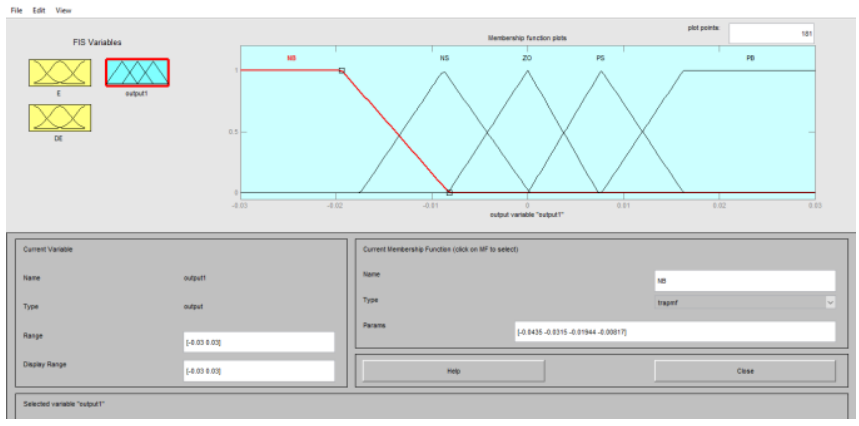

Fig 9 output rules

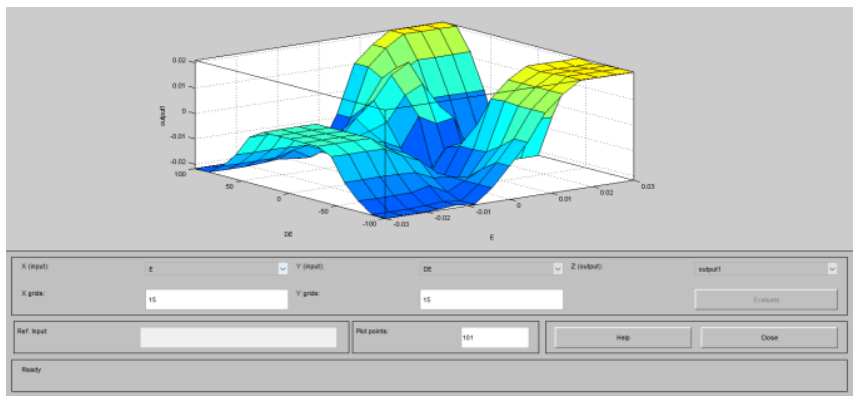

Fig 10 Fuzzy surface 


\section{International Journal of Engineering Technology and Management Sciences[IJETIIS]}

Website: ijetms.in Issue:5, Volume No.4, September-2020 DOI: 10.46647/ijetms.2020.v04i05.005

\section{CONCLUSION}

In a PV system, an FOFLC approach of MPPT is proposed. Different FO factors are used in fuzzy logic control to achieve the scalable accuracy of MPPT. One bigger factor has improved the speed and the smaller one has enhanced the tracking accuracy. An FPGAbased PV platform has demonstrated the performances of FOFLC. The simulation and experiment results indicate that the proposed method can achieve better performance under different conditions. As the fuzzy control and FO are employed, the nonlinear PV systems can be modeled and approximated. Furthermore, the system performance can be improved by optimized fractional factor. The disclosed method can also be used in other industrial fields

\section{REFERENCES}

[1] C. Hwang, J.-F. Leu, and S.-Y. Tsay, "A note on time-domain simulation of feedback fractional-order systems," IEEE Trans. Autom. Control, vol. 47, no. 4, pp. 625-631, Apr. 2002.

[2] C.-H. Lin et al., "Maximum photovoltaic power tracking for the PV array using the fractional-order incremental conductance,"Appl. Energy, vol. 88, pp. 48404847, 2011.

[3] K.-N. Yu, C.-K. Liao, and H.-T. Yau, "A new fractional-order based intelligent maximum power point tracking control algorithm for photovoltaic power systems," Int. J. Photoenergy, vol. 2015, pp. 1-8, 2015.

[4] K.-N. Yu, H.-T. Yau, and C.-K. Liao, "Development of a fractional order chaos synchronization dynamic error detector for maximum power point tracking of photovoltaic power systems," Appl. Sci., vol. 5, pp. 11171133, 2015.

[5] G. Ali Akbar, S. Seyed Mohammad, and S. Asma, "A high performance maximum power point tracker for PV systems," Elect. Power Energy Syst. vol. 53, pp. 237-243, 2013.

[6] Y. Zoua, Y. Yua, Y. Zhangb, and J. Lu, "MPPT control for PV generation system based on an improved IncCond algorithm," Procedia Eng., vol. 29, pp. 105-109, 2012.

[7] A. Sayal, "MPPT techniques for photovoltaic system under uniform insolation and partial shading conditions," in Proc. Students Conf. Eng. Syst., 2012, pp. 1-6.

[8] H. A. Sher et al., "A new sensorless hybrid MPPT algorithm based on fractional shortcircuit current measurement and P\&O MPPT," IEEE Trans. Sustain. Energy, vol. 6, no. 4, pp. 1426-1434, Oct. 2015.

[9] K. L. Lian, J. H. Jhang, and I. S. Tian, "A maximum power point tracking method based on perturb-and-observe combined with particle swarm optimization," IEEE J. Photovolt., vol. 4, no. 2, pp. 626-633, Mar. 2014.

[10] M. Farhat, O. Barambones, L. Sbita, and J. M. Gonzalez de Durana, "A stable FLC-based MPPT technique for photovoltaic system," in Proc. IEEE Int. Conf. Ind. Technol., 2015, pp. 890-895.

[11] O. Guenounou, D. Boutaib, and C. Ferhat, "Adaptive fuzzy controller based MPPT for photovoltaic systems," Energy Convers. Manage., vol. 93, pp. 1-8, 2013.

[12] Z.-J. Yang, Y.-R. Chen, and J.-M. Hu, "The research on application of variable universe fuzzy control to maximum power point tracking system," in Proc. 3rd Int. Conf. Power Electron. Syst. Appl., 2009, pp. 1-4.

[13] Y. Sun, S. Tang, Z. Meng, Y. Zhao, and Y. Yang, "A scalable accuracy fuzzy logic controller on FPGA," Expert Syst. Appl., vol. 42, pp. 6658-6673, 2015.

[14] S. Shongwe and M. Hanif, "Comparative analysis of different single-diode PV modeling 


\section{International Journal of Engineering Technology and Management Sciences[IJETIIS]}

Website: ijetms.in Issue:5, Volume No.4, September-2020 DOI: 10.46647/ijetms.2020.v04i05.005

methods," IEEE J. Photovol., vol. 5, no. 3, pp. 938-946, May 2015.

[15] M. Chengbin and H. Yoichi, "Fractionalorder control: theory and applications in motion control," IEEE Ind. Electron. Mag., vol. 1, no. 4, pp. 6-16, Winter 2007.

[16] I. Podlubny, "Fractional differential equations," Math. Sci. Eng., vol. 198, pp. 1-16, 1999.

[17] C.-L. Kuo, C.-H. Lin, H.-T. Yau, and J.-L. Chen, "Using selfsynchronization error dynamics formulation based controller for maximum photovoltaic power tracking in micro-grid systems," IEEE J. Emerg. Sel. Topics Circuits Syst., vol. 3, no. 3, pp. 459466, Sep. 2013.

[18] S. M. R. Tousi, M. H. Moradi, N. S. Basir, and M. Nemati, "A functionbased maximum power point tracking method for photovoltaic systems," IEEE Trans. Power Electron., vol. 31, no. 3, pp. 2120-2128, Mar. 2016.

[19] H. Rezk and A. M. Eltamaly, "A comprehensive comparison of different MPPT techniques for photovoltaic systems," Sol. Energy, vol. 112, pp. 1-11, 2015.

[20] Y. Mahmoud, M. Abdelwahed, and E. F. El-Saadany, "An enhanced MPPT method combining model-based and heuristic techniques," IEEE Trans. Sustain. Energy, vol. 7, no. 2, pp. 576-585, Apr. 2016.

[21] S. Lyden and M. E. Haque, "Simulated annealing global maximum power point tracking approach for PV modules under partial shading conditions," IEEE Trans. Power Electron., vol. 31, no. 6, pp. 4171-4181, Jun. 2016.

[22] A. M. Eltamaly, "Performance of smart maximum power point tracker under partial shading conditions of PV systems," in Proc. IEEE Int. Conf. Smart Energy Grid Eng., 2015, pp. 1-8.

[23] B. N. Alajmi, K. H. Ahmed, S. J. Finney, and B.W.Williams, "A maximum power point tracking technique for partially shaded photovoltaic systems in micro grids," IEEE Trans. Ind. Electron., vol. 60, no. 4, pp. 15961606, Apr. 2013. 